\title{
Hot Rolling of Large Gears
}

\author{
Dirk Landgrebe, Andreas Sterzing, Mike Lahl, Thomas Druwe, Anne Manuela Taubert \\ Department of Bulk Metal Forming, Fraunhofer Institute for Machine Tools and Forming Technology (IWU), Chemnitz, Germany \\ Email: anne.manuela.taubert@iwu.fraunhofer.de
}

How to cite this paper: Landgrebe, D., Sterzing, A., Lahl, M., Druwe, T. and Taubert, A.M. (2017) Hot Rolling of Large Gears. Open Access Library Journal, 4: e3152. https://doi.org/10.4236/oalib.1103152

Received: October 17, 2016

Accepted: February 19, 2017

Published: February 22, 2017

Copyright $\odot 2017$ by authors and Open Access Library Inc.

This work is licensed under the Creative Commons Attribution International License (CC BY 4.0).

http://creativecommons.org/licenses/by/4.0/

\begin{abstract}
Forming processes are generally characterized by a high degree of material utilization as well as short process times and, consequently, a decent economic efficiency. Furthermore, incremental forming enables the use of relatively low forming forces which results in a more compact design of the used machines. These conveniences are utilized in terms of roll forming with round tools to form gears and threads in a competitive way. Based on experiences gained over many years of researching rolling technologies, a cross-rolling process characterized by round tools with outer gearings was elaborated to realize a hot forming process of large gears at the Fraunhofer IWU. At actual project GEARFORM, a scaled sun gear demonstrator from wind gear application could be realized by hot rolling technology. An optimized rolling time was achieved by 32.5 seconds.
\end{abstract}

\section{Subject Areas}

Metal Material

\section{Keywords}

Hot Forming, Gear Rolling, Large Module, Inductive Heating

\section{Introduction-General Rolling Technology Description}

Former cold rolling processes for gear production received an industrial acceptation limited to stub-toothed geometries with tooth height coefficients up to $\mathrm{y}=$ 1.5. However, findings of the researches at Fraunhofer IWU Chemnitz prove that it is possible to roll high gearings by using a wedge-rolling technique with two round tools for transmission applications, as well as other rotationally symmetric profile shapes [1]. In regard to optimizing the forming process, the tool design and its construction numerous optimization loops were necessary to ensure the required component qualities. Due to the increase of available computing capacities and the latest findings in the simulation of incremental forming 
technologies, an illustration of the demanding process kinematics was made possible. Compared to earlier FE calculations, a 32-core computer could be used instead of an 8-core one. Moreover, the segmentation strategy of work piece geometry led to an enormous time reduction. The round-rolling process with two rolling tools can be considered as a forming process with infinite tool length. Accordingly, the maximum tip diameter of a rollable work piece is only limited by the available working space of the utilized machine. The rotationally symmetric work piece is clamped between tips or chucked with a single centering tip in axial direction. The round-rolling tools start penetrating from the pre-diameter of the workpiece having the same rotational direction and constant speed each. Next, the forming process is introduced by reducing the distance between the axes of the tools in the radial direction. Based on a calculation and improved construction of the tools a parameter related process optimization was accomplished by the Fraunhofer IWU Chemnitz. Thus, it was possible to roll spur and helical gears with a tooth height coefficient outreaching the state-of-the-art values into the solid material using a special rolling machine called PWZ. This expanded the limits for rollability by extending the tooth height coefficient of rolled gears by factor four compared to former investigations [2].

\section{Rolling Machine}

In initial trials using existing machine technology at the Fraunhofer IWU promising results at planetary gears could already be achieved with the approach of round rolling principle (see process of heating and hot rolling in Figure 1). For the purposes of the desired diameter range of large gears an appropriately sized and adapted hot rolling technology could be developed by adjusting the PWZS pezial rolling machine.

At the beginning of the forming process, the work piece is accelerated to the correct rotational velocity (see Figure 2).

Compared to a cross-rolling with flat jaws, the amount of seams is not limited by the dimensions of the work piece. Furthermore, the kinematic of the rolling tools can be programmed freely over operated axes. Hereby, the following process sequence is designated concerning the hot forming of gears:

1. Insertion and chucking of the cold preform.

2. Moving the preform and the inductor in the heating position.
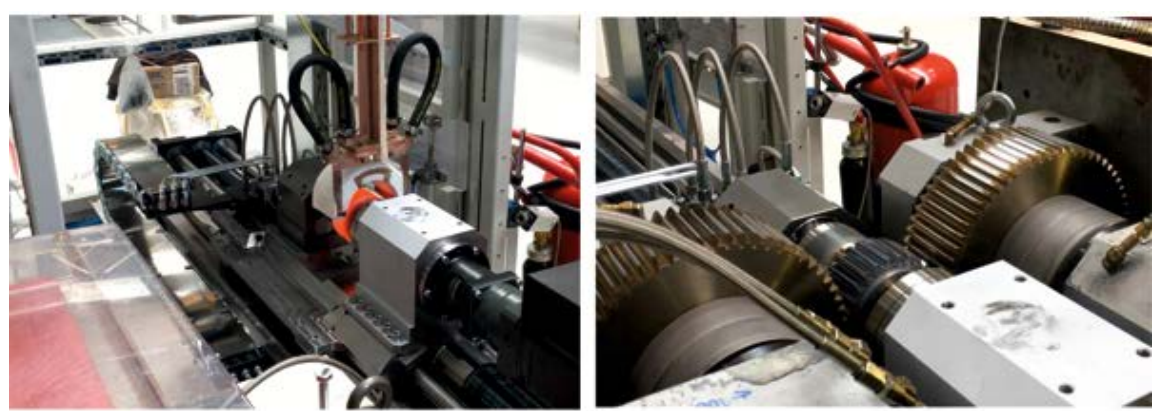

Figure 1. Inductive heating (left) and hot rolling (right). 


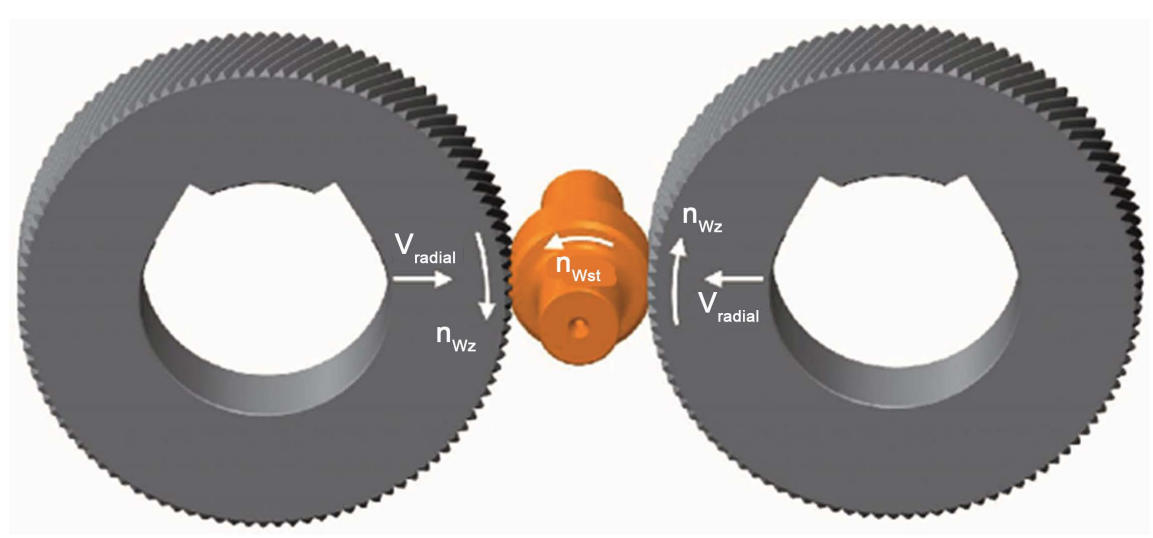

Figure 2. Rolling kinematic.

3. Inductive heating of the preform's surface.

4. Moving of the preform to the rolling position.

5. Gear rolling.

6. Moving the work piece to the removal position.

7. Relaxation and withdrawal of the work piece with optional quenching.

\section{Tools and Devices}

In order to guarantee a rolling process which generates gears of the desired quality, the tool design, the clamping units as well as the used preforms have to be considered. Therefore, the following articles contain a summary of the geometrical and mechanical adjustments to realize the hot forming of large gears [3] by gear rolling.

\subsection{Design of Workpieces}

In terms of down-scaling the desired demonstrators to the common size of the present rolling machine used at the Fraunhofer IWU, the available working space as well as the performance characteristics of the rolling drive concerning the rolling force and the corresponding torque have to be considered. Therefore, the maximum of the work piece diameter can be characterized by 200 millimeters which can be attributed to the peculiarity of the tool's own diameter and the maximal distance between the tool axes. Considering the scientific and technological results of prime rolling trials, that can be defined by the utilization of tools used for hot forming work pieces with a mean temperature of $1000^{\circ} \mathrm{C}$, it was possible to determine that torque provided by the tool's drive was suitable to realize the forming of gears with a normal module of 4 millimeters and a width up to 90 millimeters. Based on these circumstances, the scaling was performed, see Table 1.

In case of the demonstrator, the so-called sun gear, the normal module was multiplied by 4 in order to scale it up. However, the parameters resulting from this process are still realizable by the rolling machine PWZ Spezial. Eventually, the width of the work piece had to be reduced when reaching the torque limit of the rolling drive, see Figure 3. 

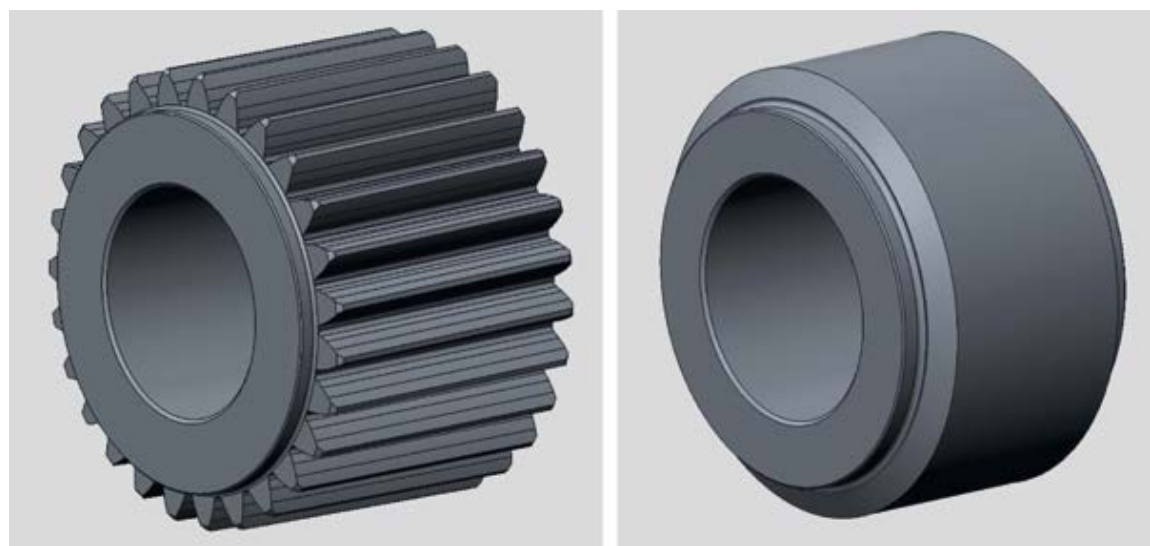

Figure 3. CAD models: scaled sun gear (left), temporary rolling preform (right).

Table 1. Scaling of the demonstrators.

\begin{tabular}{ccc}
\hline Parameter & Original sun wheel & Scaled demonstrator \\
\hline Normal module [millimeter] & 16 & 4 \\
Number of teeth & 27 & 27 \\
Width [millimeter] & 360 & 90 \\
Tip diameter [millimeter] & 491.4 & 122.86 \\
Material & 18CrNiMo7-6 & 18CrNiMo7-6 \\
\hline
\end{tabular}

\subsection{Design of Workpiece Clamping}

The constructive adjustments of the rolling machine mentioned were generally approved. The production of the single machine components as well as the installation of major assembly groups and the final reconstruction of the machine was carried out by the company Dreiling which is located in Geisleden, Germany. The base frame consisting of a welded construction, the base plate with the sliding carriage on top, the head- and tailstock montaged on the sliding carriage are displayed in Figure 4.

Furthermore, the assembly contained newly developed spindles, which were exclusively produced to be part of the PWZ Spezial of the Fraunhofer IWU and support the use of tool widths up to 180 millimeters. Besides, a convenient coating of the spindle's surface prevents the development of rust attributed to the designated fitting which can occur between the tool and the spindle. It also stabilizes the rolling process in case of forming high-tempered work pieces.

\subsection{Design of Rolling Tools}

The construction of the rolling tools at the Fraunhofer IWU was carried out based on the sun gear. Likewise, the profile design of the tools was created by a process of rolling off the desired gear contour. Here, the tip diameter of the tool, which adds up to the volume of the work piece and its amount of teeth, has to be defined [4] [5] [6] [7] [8]. The unique contour of the bore which is part of the tools results from requirements of the used tool holder of the PWZ Spezial. The parameters which characterize the tool used for the forming of the sun gear and a corresponding 3D-model can be seen in Figure 5. 

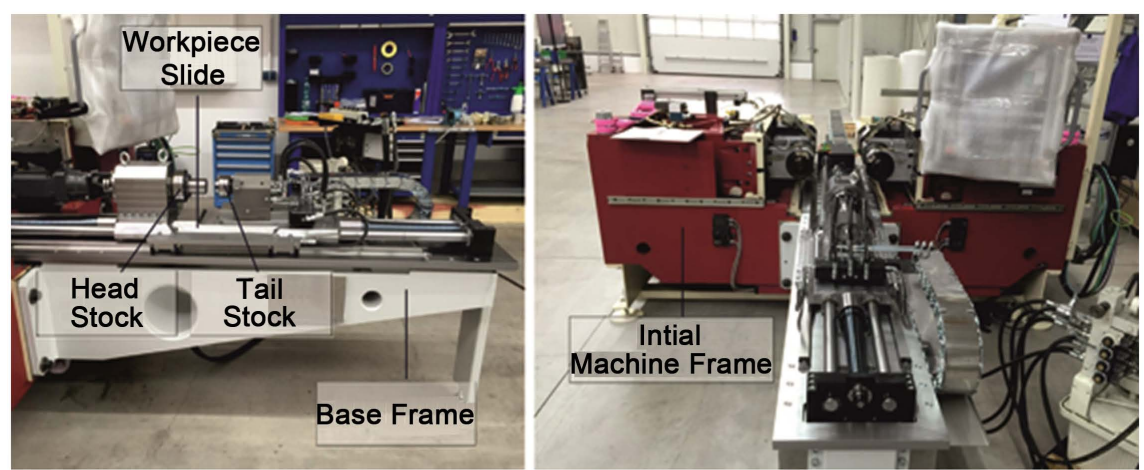

Figure 4. Assembly group consisting of the base frame, the sliding carriage, the tail- and headstock seen from the $\mathrm{x}$ - (left) and $\mathrm{z}$ direction (right).

\begin{tabular}{cc}
\hline Parameter & Value \\
\hline Normal module [millimeter] & 4.00 \\
Number of teeth [-] & 65 \\
Helix angle [degree] & 1.5108 \\
Pitch circle diameter [millimeter] & 260.09 \\
Lead [millimeter] & 30980.56 \\
Lead direction & Right \\
Tip diameter [millimeter] & $276.852 \pm 0.05$ \\
Tooth root diameter [millimeter] & 257.982 \\
\hline
\end{tabular}

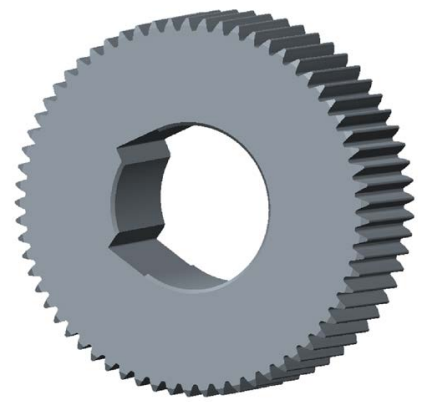

Figure 5. 3D-model of the rolling tool for the forming of the sun gear and corresponding parameters.

Basically, gear rolling can be characterized as a compressive forming process. In this regard, two round tools with outer gearings form the designated gear geometry into the work piece by a combining a rotational with a radial tool feed motion. In the following case, the used forming process can be defined as a hot forming one using work piece temperatures of $900^{\circ} \mathrm{C}$ to $1200^{\circ} \mathrm{C}$. The tool teeth are subjected to bending stresses. Since the effective contact time between the work piece and the tool is generally short there is a relatively low thermal impact on the tool, too, resulting in a comparatively slight elevation of the tool temperature of $350^{\circ} \mathrm{C}$. It has to be mentioned that there might be a higher temperature at the teeth tips, which is, however, locally limited. Nevertheless, the following main requirements of the tool material can be derived from the described research results:

- Extreme toughness combined with a decent hardness,

- Good tempering resistance,

- Adequate thermal shock resistance,

- Abrasion resistance,

- Available in a diameter range up to 1000 millimeters.

Considering these requirements, the hot working steel TQ1 provided by the Kind \& Co. stainless steel mill was the material of choice. 


\section{FE Simulation}

The entireness of the following simulations was carried out by using the simulation software Forge computed by the Transvalor Company. In case of the sun gear the expansion of the preform diameter due to the temperature rise as well as the temperature distribution in the forming zone was analyzed. Defining the exact extent of the preform diameter is a crucial task for ensuring a fully functional rolling process and to guarantee the correct rolling of the designated amount of teeth. Besides, the temperature distribution in the forming zone of the preform is a significantly relevant information. The inductively applied forming temperature has to be appropriately high in the area of the tooth root diameter to ensure an adequately ductile material behavior of the work piece. Furthermore, diverse feed motions of the tool and the subsequently resulting stresses on the tools were analyzed.

\subsection{Simulation of Inductive Heating}

The results which could be achieved by simulating the heating of the preform are displayed in Figure 6. As the temperatures in the outer area of the tooth root diameter reach degrees of about $900^{\circ} \mathrm{C}$, an extension of the preform diameter of about $1.2 \%$ can be witnessed.

\subsection{Simulation of Hot Rolling Process}

After the simulation of the heating process, the flow of the used material was numerically simulated and evaluated by using a hot-forming simulator. Based on the achieved findings, further preforms were developed which should be designed to optimize the flow of material. In order to reduce the time needed for simulating, the main focus of this research was put on a single segment of the

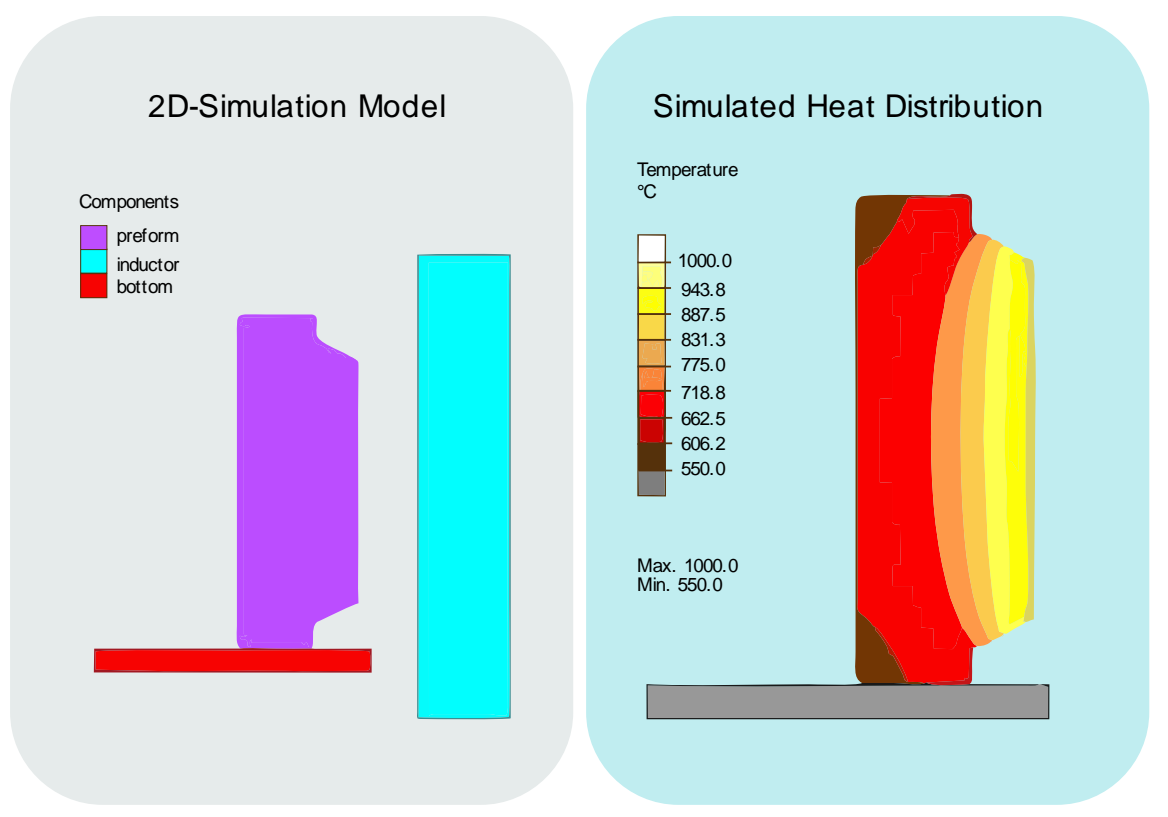

Figure 6. Scientific results of simulating the heating of the preform. 
gear's entireness. In Figure 7, the designated finite element model including both tools, the tool holder, the mandrel and the preform can be seen. Additionally, the preform was constructed with a finer FEM net in the relevant contact zone. Furthermore, a supplementary plane of symmetry was added in the axial direction to reduce the amount of element knots.

Following the simulation of the forming process of the preform further calculations are executed. The first model used contained a cylindrical bore in a concave preform characterized by a phase angle of $30^{\circ}\left(120^{\circ}\right)$ and a step slanted in $90^{\circ}$. Besides, the simulated result of the rolling process is displayed in Figure 8 in an over layered matter, presenting the cold-forming condition (green) and the preform (red). Due to this layout the development of the undercut as well as of the significant axial flow of material are highlighted. The gear used for the finite element model is defined by a fully formed tip up to a width of 55.7 millimeters, a tip circle of 123.9 millimeters and a root circle of 104.9 millimeters.

Forge Model

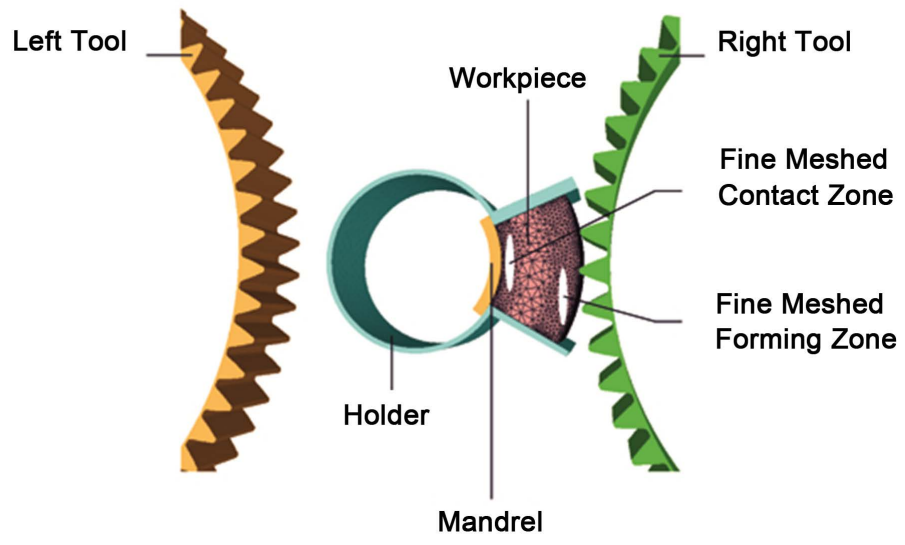

Figure 7. Finite element modell used for simulating the hot-forming process of the gear.

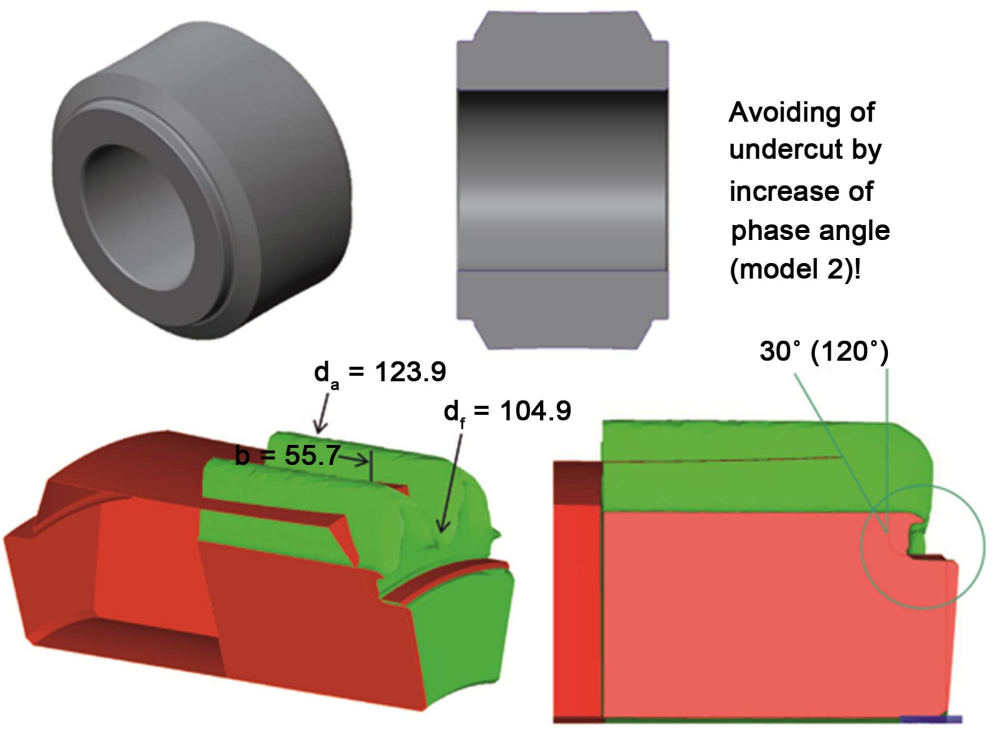

Figure 8. Model 1 of the finite element simulation at room temperature. 
In order to optimize the contour of the gear on both fronts a second model including an increased phase angle of $35^{\circ}\left(125^{\circ}\right)$ and the elimination of the previous step geometry was developed (see Figure 9 ). Due to that, the development of the undercut could be reduced drastically. Besides, the fully possible formation of the tip increased to 60 millimeters. These slightly increased diameters can be attributed to a rise in the volume of the simulation model, which can hardly be controlled using the present software.

Due to the utilization of a simulation model focusing on a single segment of the work piece the calculation of the demanded forming force was realized. According to the findings of this research, the forming force grows continuously during the penetration of the work piece up to a maximum of 300 kilo newton, as displayed in Figure 10. Therefore, the process of calibration utilizes $75 \%$ of the maximum machine capacity which can be quantified by 400 kilo newton, respectively.

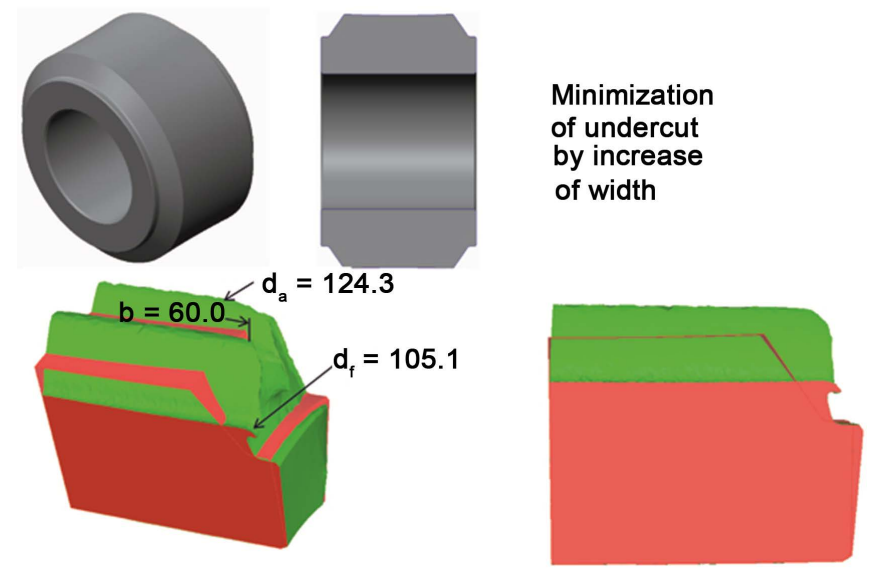

Figure 9. Model 2 of the finite element simulation at room temperature.

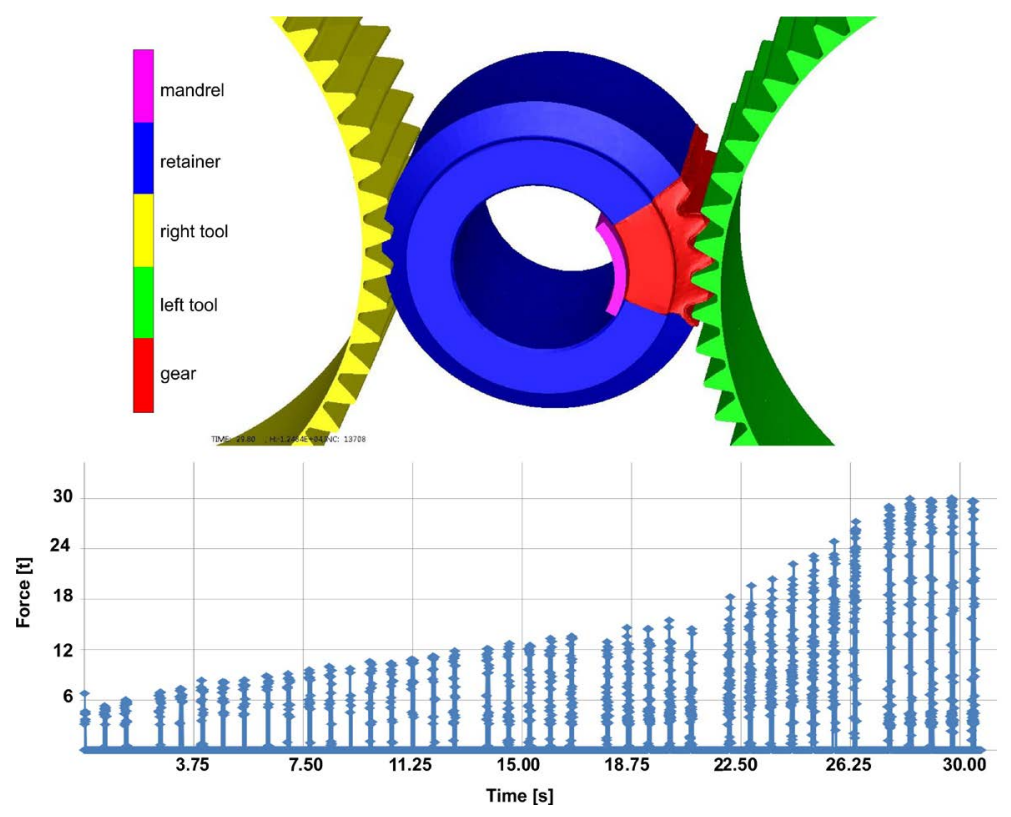

Figure 10. Simulation of demanded forming forces during the hot rolling of the sun gear. 


\section{Verification Rolling Trials}

After testing the segment inductor in the context of heating experiments the first rolling experiment was executed utilizing the most dedicated adjustments, based on the prior simulated findings, and a work piece temperature of $900^{\circ} \mathrm{C}$. However, the verification of the rolling trials was not solely based on the results ofthe above-mentioned experiments, but also on a forming expertise gained over many years of innovative research. Therefore the depth of tool penetration was reduced in the first establishing trials to monitor the workload of the rolling machine concerning the force and torque. Initially, the number of work piece revolution was set to 43 , which engendered in parallel with a tool rotation speed of $\mathrm{n}=40 \mathrm{~min}^{-1}$ by teeth ratio $65: 27$ to a rolling time of 32.5 seconds. To realize symmetric teeth forming process, 6 rotation reversals were implemented to penetration path. Figure 11 displays the actual-value diagram of this experiment, showing the force development $\left(\mathrm{F}_{\max }=146.2\right.$ kilo newton $)$ in a blue and the torque development $\left(\mathrm{T}_{\max }=386.4\right.$ newton meter $)$ in a red color with a reduced penetration depth $(\mathrm{x}=10.2$ millimeters $)$.

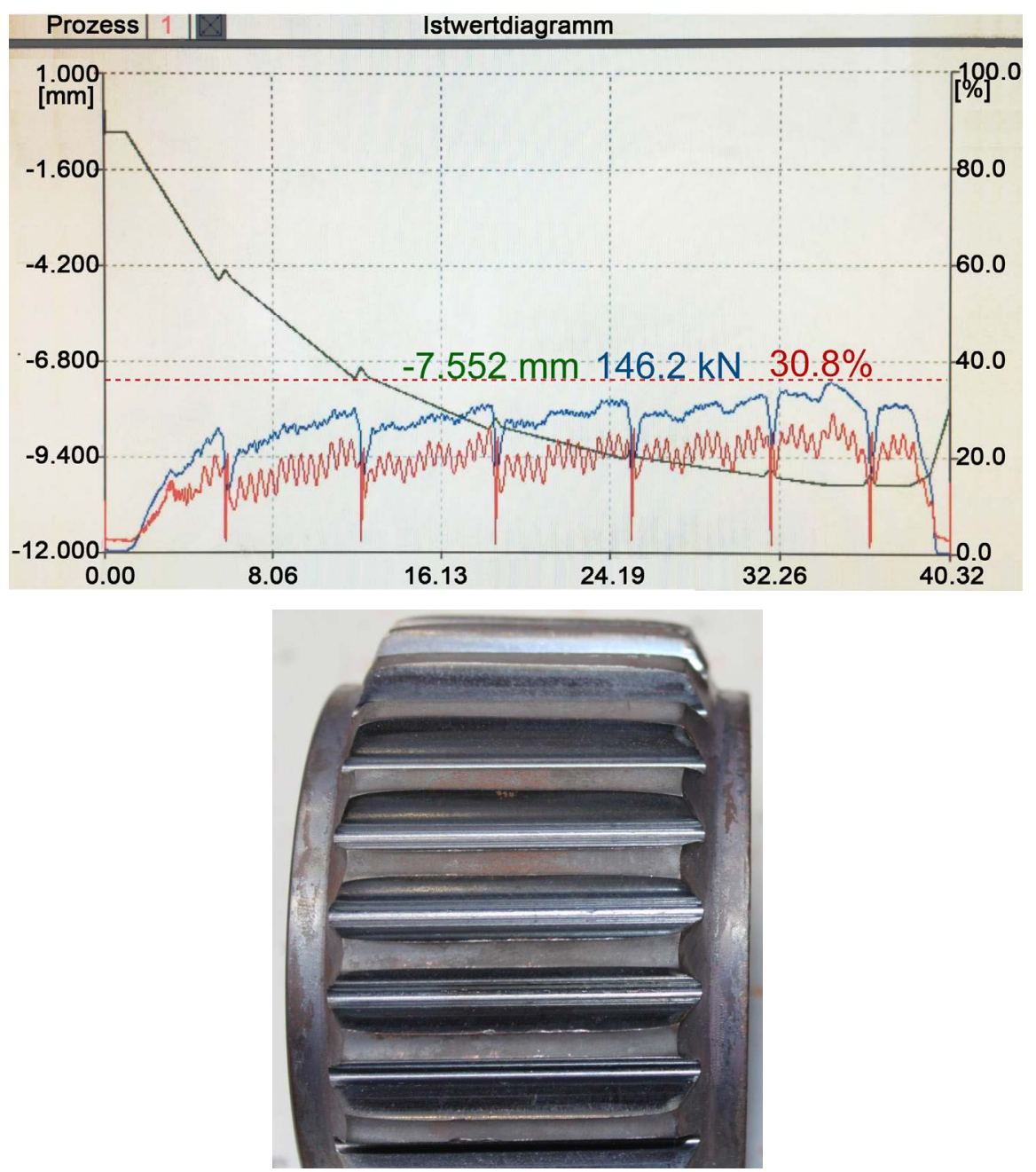

Figure 11. Acutal-value diagram using a reduced tool penetration depth and the correspondingrolled part. 
Then, the depth of penetration was increased gradually ( $x=14.2$ millimeters) in subsequent experiments until the gear was fully formed, see Figure 12. The blue force curve increased to $\mathrm{F}_{\max }=294.8$ kilo newton and the red torque curve increased to $\mathrm{T}_{\max }=1140.9$ newton meter).

To determine the influence of the work piece's size on the development of the needed rolling force and torque more detailed, preforms of divergent widths were used in following experiments, see Figure 13. In regards of calculating the demanded force for rolling the demonstrational gears, the influence of the preform width was analyzed compared to the original size of the work piece. In Table 2 you can see the values of both sizes. The increasing part width is resulting

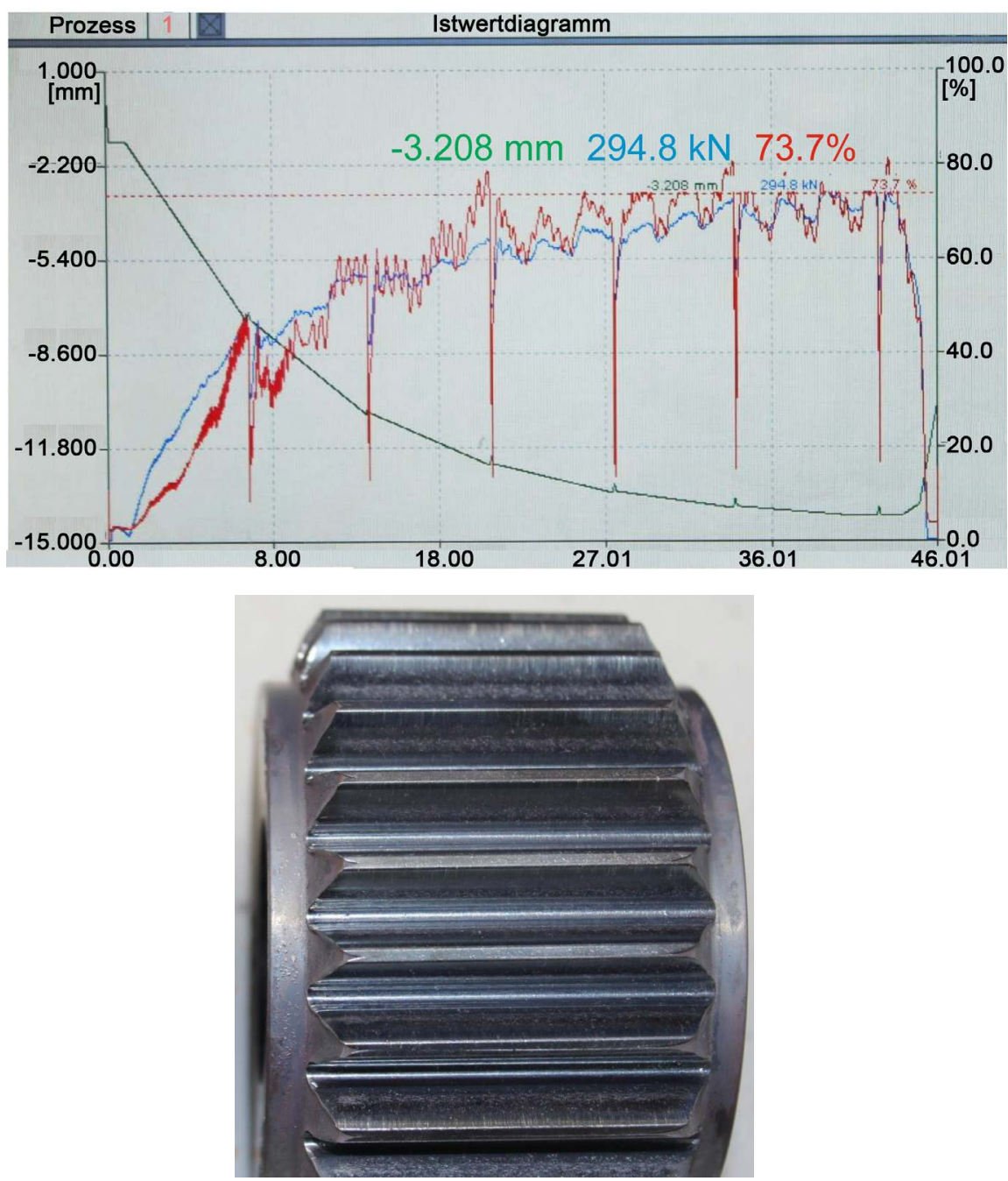

Figure 12. Acutal-value diagram using an increased tool penetration depth of $70 \%$ of the machine's maximum capacity (left) and the corresponding rolled part (right).

Table 2. Force and torque values for different widths.

\begin{tabular}{ccc}
\hline Part width [millimeter] & Max. torque [newton meter] & Max. force [kilo newton] \\
\hline 60 & 1100 & 200 \\
74 & 1220 & 210 \\
\hline
\end{tabular}




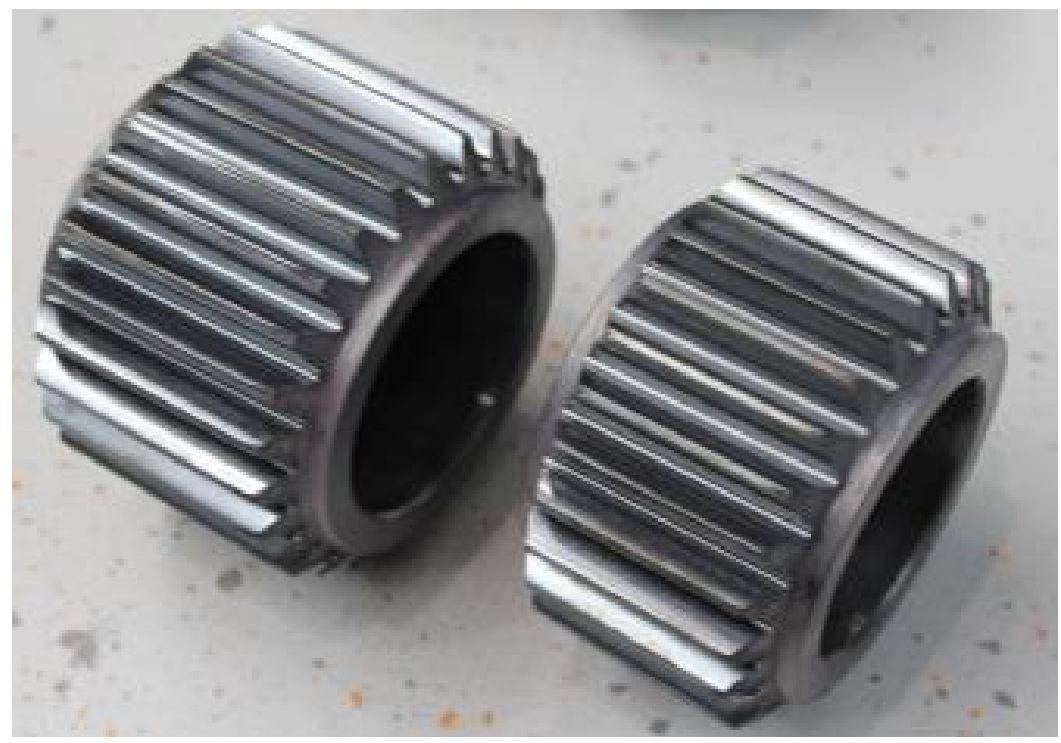

Figure 13. Rolled parts with divergent widths.

in a significant increase of torque value during rolling. The force value is changing marginally.

Temperature measurements were conducted during the rolling experiments in order to determine the work piece temperature over whole process. The pyrometer was focused at work piece middle section to measure the surface temperature during inductive heating and after rolling at workpiece re-clamping position (see Figure 1, left). Figure 14 displays the measured temperatures. The temperature rises up to the designated forming temperature before the work piece is moved to the rolling position and subsequently formed. Here, the value of $240^{\circ} \mathrm{C}$ displays the minimum of measurable temperature of the pyrometer (see Figure 1, right) - this time slot can be ignored. Afterwards the work piece returns to changing position, ready to be removed from the machine. The mean surface temperature in this position was quantified by $580^{\circ} \mathrm{C}$.

\section{Conclusions and Outlook}

The successful forming of large gears on the PWZ Special machine can be attributed to the adjustment of the tool clamping unit as well as the integration of a segment inductor. The verification of the hot-forming process was made possible by simulating the tool together with the preform design and the force demanded for rolling. Additionally, experimental trials were executed.

Referred to the temperature measurements at maximum output of induction unit an up-scaled heating system must be used to minimize heating time in parallel with increase of forming temperature for further hot rolling trials.

The main focus of future research can be defined by the derivation of the designated machine parameters for rolling large gears in real-life dimensions. Also, the execution of rolling trails utilizing a new hot-forming machinery to realize large gears with outer diameters of up to 1000 millimeters will be a crucial aspect of upcoming scientific considerations. 


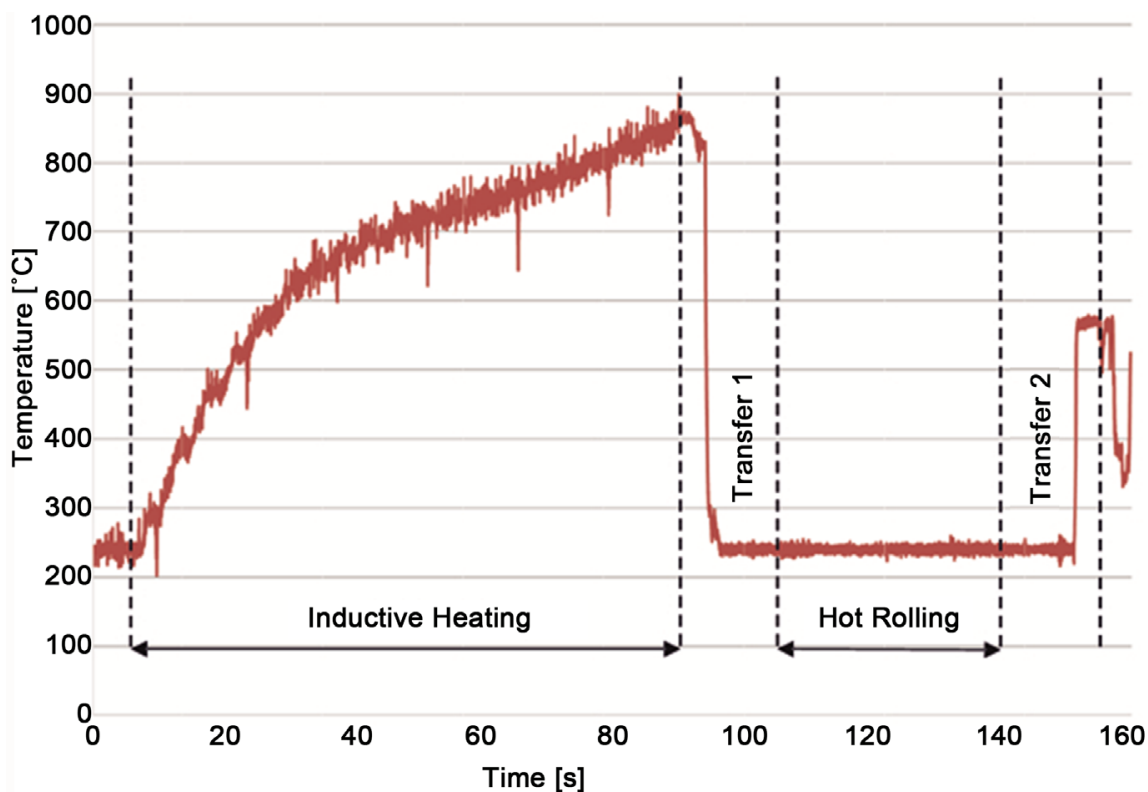

Figure 14. Temperature measured over whole process.

\section{Acknowledgements}

The project "GEARFORM: Energie-und ressourceneffiziente Umformunggroß moduliger Zahnräder" is financed by the Federal Ministry for Economic Affairs and Energy (BMWi) within the framework of the "6. Energieforschungs programm" (Project number 03ET1201A-F).

\section{References}

[1] Neugebauer, R. and Lorenz, B. (1999) Neueste Entwicklungen auf dem Gebiet des Querwalzens, Neuere Entwicklungen in der Massivumformung, Stuttgart.

[2] Neugebauer, R., Dube, H. and Kolbe, M. (2000) Prozessketten der Massivumformung unter Aspekten der Produktivität und Umweltverträglichkeit. Verlag Wissenschaftliche Scripten, Zwickau.

[3] Gasch, R. and Twele, J. (2010) Windkraftanlagen-Grundlagen, Entwurf, Betrieb. 7. Auflage, B.G. Teubner, Stuttgart.

[4] Hellfritzsch, U. (2001) Verfahren und Maschinen für das Walzen von Verzahnungen, Praxis der Umformtechnik, 6. Auflage, Vieweg Verlag Braunschweig.

[5] Hellfritzsch, U. and Strehmel, P. (2002) Walzen statt Spanen in der Stirnradfertigung. Werkstatt und Betrieb, 135, 54-56.

[6] Neugebauer, R. and Hellfritzsch, U. (2007) Improved Process Design and Quality for Gear Manufacturing with Flat and Round Rolling. International Institution for Production Engineering Research CIRP, 57 th General Assembly of CIRP, Dresden, 307-312.

[7] Neugebauer, R., Hellfritzsch, U. and Lahl, M. (2008) Advanced Process Limits by Rolling of Helical Gears. 11 th ESAFORM Conference on Material Forming, Lyon.

[8] Neugebauer, R., Hellfritzsch, U., Lahl, M. and Schiller, S. (2008) Optimierung des Walzprozesses hoher Laufverzahnungen, VDI-Tagung Getriebe in Fahrzeugen, Friedrichshafen. 
Submit or recommend next manuscript to OALib Journal and we will provide best service for you:

- Publication frequency: Monthly

- 9 subject areas of science, technology and medicine

- Fair and rigorous peer-review system

- Fast publication process

- Article promotion in various social networking sites (LinkedIn, Facebook, Twitter, etc.)

- Maximum dissemination of your research work

Submit Your Paper Online: Click Here to Submit

Or Contact service@oalib.com 